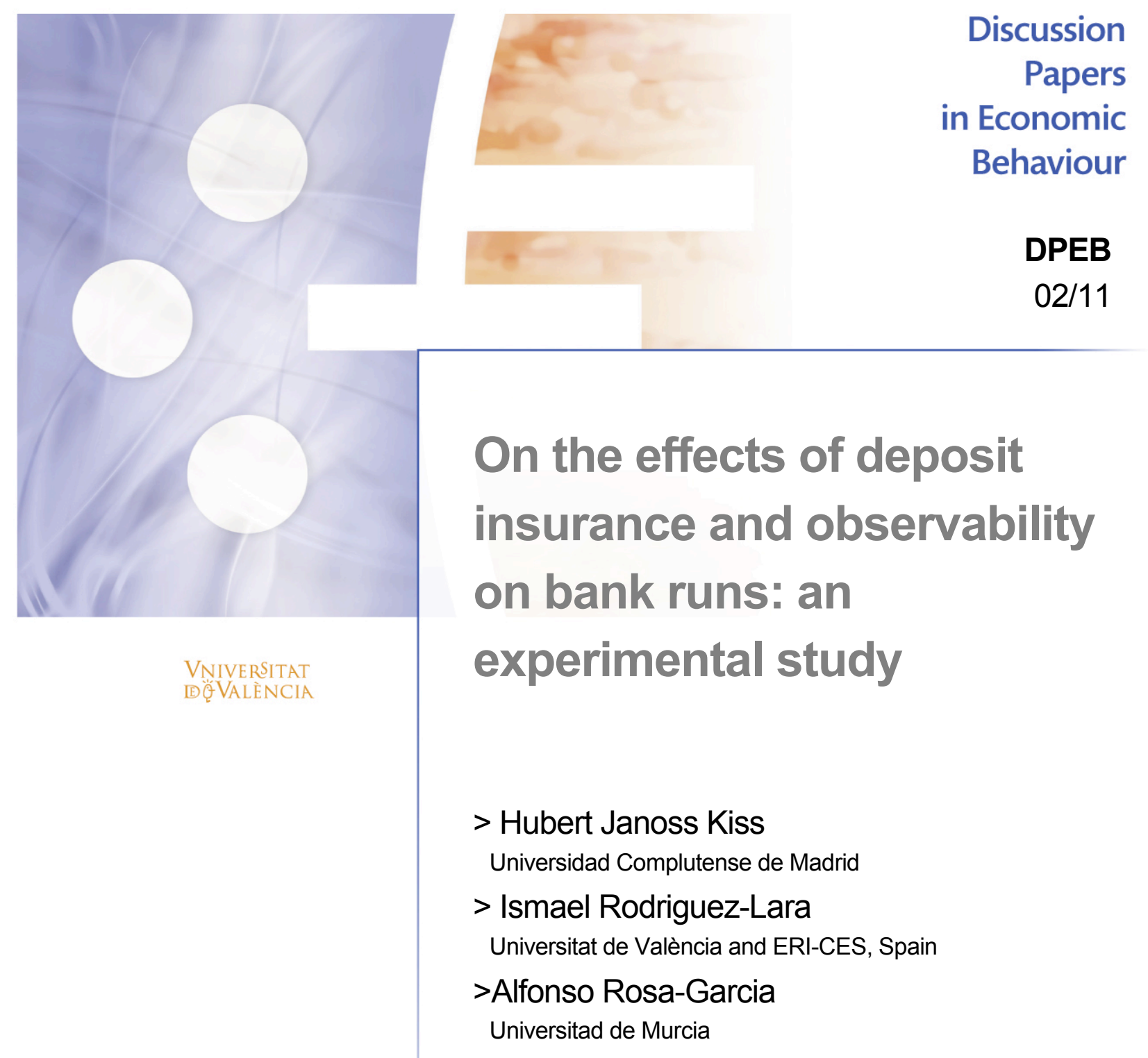




\title{
On the Effects of Deposit Insurance and Observability on Bank Runs: An Experimental Study*
}

\author{
Hubert Janos Kiss ${ }^{\dagger} \quad$ Ismael Rodriguez-Lara ${ }^{\ddagger} \quad$ Alfonso Rosa-García ${ }^{\S}$
}

February 1, 2011

\begin{abstract}
We study the effects of deposit insurance and observability of previous actions on the emergence of bank runs by means of a controlled laboratory experiment. We consider three depositors in the line of a common bank. Depositors decide in sequence between withdrawing or keeping their money deposited. We have three different treatments in which depositors who keep the money have full insurance, are partially insured, or not insured at all in case of a bank run. We find that different levels of deposit insurance and the possibility of observing other depositors' actions reduce the likelihood of bank runs. The effect of these variables is not independent. Our data suggest that optimal deposit insurance should take into account the degree of observability: full and partial insurance are equally effective when decisions are observable, whereas full insurance is more likely to prevent bank runs when depositors do not observe other depositors' decisions.
\end{abstract}

Keywords: deposit insurance, observability, bank runs, experimental economics.

JEL Classification: G21, C90

${ }^{*}$ We are indebted to Luis Moreno-Garrido for his contribution to the experimental design. We would also like to thank Coralio Ballester, Lola Collado and Jaromir Kovarik for helpful comments. Finally, this paper has benefitted from suggestions provided by participants of the XXXV Simposio Asociación Economía Española (SAEe) and M-BEES Maastricht 2010. Financial support from Spanish Ministry of Education and Science (SEJ2007-62656) is gratefully acknowledged. The authors kindly acknowledge financial support from the Spanish Ministry of Science and Innovation under the project number ECO 2008-00510 (Hubert Janos Kiss) and ECO2010-19830 (Alfonso Rosa-García).

†(Corresponding Author) Departamento Análisis Económico, Universidad Autónoma de Madrid, Cantoblanco, 28049 Madrid, Spain. E-mail address: hubert.kiss@uam.es.

‡ERI-CES, Departamento de Análisis Económico, Universidad de Valencia, Campus dels Tarongers. Avda. dels Tarongers s / n. 46022 Valencia, España. E-mail address: Ismael.Rodriguez@uv.es.

$\S$ Dpto. de Fundamentos del Análisis Económico. Facultad de Economía y Empresa. Universidad de Murcia, Campus de Espinardo. 30100 Murcia. E-mail address: alfonso.rosa@um.es. 


\section{Introduction}

This paper investigates how deposit insurance and observability affect the emergence of bank runs by means of a controlled laboratory experiment. In 2007, the run on Northern Rock heralded the recent financial turmoil. This bank suffered massive withdrawals within days despite that bank deposits in the UK were insured. ${ }^{1}$ Media coverage that made observable the lines in front of the bank offices might have contributed to the protraction of the run.

Deposit insurance is regarded as one of the pillars of modern financial safety nets. The main objective of deposit insurance is to protect depositors who cannot generally make an informed assessment of the risk that the bank to which their funds are entrusted may fail. During the recent crisis, one of the public aims has been to maintain the confidence in the financial intermediation and to avoid runs on banks without fundamental problems. To this purpose, the level of deposit insurance has been increased in the EU (Directive 2009/14/EC), and national governments took discretionary measures (e.g. the Dutch government's injection of EUR 10 billion into the ING group).

Observing other depositors' actions is an important issue as testified by descriptions of real-world bank runs (Sprague, 1910; Wicker, 2001) and by statistical data on run episodes (Starr and Yilmaz 2007). These studies make clear that depositors' decisions are not simultaneous, but many depositors have information about what other depositors have done and react to this information when making their decisions (Kelly and O Grada, 2000; Iyer and Puri, 2008). ${ }^{2}$

We design an experiment to study how different levels of deposit insurance and observability of actions affect the emergence of bank runs. The lack of detailed data about depositors' behavior in real-world situations complicates the analysis of these issues. Carrying out laboratory experiments that mimic bank run situations may be a fruitful way to shed light on the effectiveness of different levels of deposit insurance, given various degrees of observability.

Our experiment resembles a bank-run environment with three depositors in the line of a common bank, in which earlier they deposited their endowments (40 monetary units). Depositors are randomly assigned a position (that is made known to them) in the sequence of decision and choose between waiting or withdrawing their money from the bank, according to their position. ${ }^{3}$ Each depositor knows her own liquidity needs, which

\footnotetext{
${ }^{1}$ They were fully insured up to GBP 2000 , and $90 \%$ of the deposits was insured above this sum up to GBP 35000 .

${ }^{2}$ The idea of sequential decisions, however, is absent in most of the theoretical literature on bank runs, which builds on the seminal paper by Diamond and Dybvig (1983) and considers simultaneous decisions. Gu (2009) incorporates the idea of observability, and focuses on a signal extraction problem in which depositors try to find out whether their bank has fundamental problems or not.

${ }^{3}$ We use "keeping the money deposited" and "waiting" in an interchangeable manner. The assumption about the perfect
} 
is private information. Following the literature, we consider two types of depositors. There is an impatient depositor who has an immediate need for funds and always withdraws her deposit. The other two depositors are the patient ones. They do not need their money urgently and decide whether to withdraw their funds from the bank or keep them deposited.

Whether the other depositors' decisions are observable is determined by the position in the sequence and the informational setup. In this paper, we focus on two setups: the simultaneous and the sequential one. In the simultaneous setup depositors do not have any information about what other depositors have done whereas in the sequential setup each previous decision is observable and depositors that act early are aware that their decisions will be observed.

In the experiment, patient depositors choose between waiting or withdrawal during 15 rounds, with variation of information and position in each round. If both of the patient depositors decide to wait, they receive the highest possible payoff (70 monetary units). Withdrawal yields a lower, but a still relatively high payoff (50 monetary units) to the first two depositors who decide to withdraw, regardless of their liquidity needs. The payoff for a depositor that withdraws after two withdrawals is 20 monetary units. Deposit insurance becomes relevant when a patient depositor waits alone. In this case, we consider three possible payoffs which correspond to three different treatments. When there is no insurance, the patient depositor who waits alone receives a payoff (20 monetary units) that is so low as the payoff she would receive upon withdrawal once the other two depositors have withdrawn. ${ }^{4}$ In the case of partial deposit insurance, the patient depositor who waits alone receives a payoff (30 monetary units) that is lower than the initial endowment and lower than the payoff to the first two withdrawing depositors. Nevertheless, it is higher than the payoff in the no-insurance case. In the full insurance case, a depositor who waits alone receives her initial endowment (40 monetary units). Hence, when there exists full insurance a patient depositor cannot lose money compared to the initial endowment, but still the first and second depositors to withdraw receive a higher payoff. Given these payoffs, bank runs can be approached as a coordination problem, meaning that a patient depositor prefers to wait if the other patient depositor does so as well.

In this environment, we define a bank run as a situation in which at least one of the patient depositors withdraws. While previous experiments study how the likelihood of bank runs varies as the level of deposit insurance changes, ours allows also for variation in observability. This new dimension is shown to be relevant since others' decision may affect our choices, and it is in fact which occurs in the experiment. The possibility knowledge of the position is often considered in theoretical models (Andolfatto et al., 2007; Green and Lin, 2000; Ennis and Keister, 2009).

${ }^{4}$ Since the bank starts with $3 \times 40=120$ monetary units, after two withdrawals that yield 50 monetary units, the bank has only 20 units to be paid to the depositor who waits. 
of observing early withdrawals may spark off a bank run despite high levels of deposit insurance. Though, if early depositors are observed to keep the money in the bank, then the effect may be making bank runs rare. The experimental data show that observability plays a role in the emergence of bank runs as the sequential setup decreases significantly the likelihood of bank runs with respect to the case of simultaneous decisions. As expected, deposit insurance is also important in reducing the likelihood of bank runs since both partial and full insurance decrease the likelihood of bank runs in any of the two setups. Indeed, both the partial and the full insurance are more important than observability in reducing the likelihood of bank runs in the simultaneous setup.

When investigating the interplay between the different levels of insurance and observability we find that their effects are not independent. If decisions are not simultaneous but sequential, we find that deposit insurance decreases the likelihood of bank runs, but the effects of full and partial insurance are not significantly different. This is the main contribution of the paper, since it shows that the effectiveness of different levels of deposit insurance depends on the degree of observability, a finding that is absent in the literature. This fact has policy implications, since it implies that in an environment characterized by high level of observability preventing bank runs is less costly, and minimizing the likelihood of bank runs and keeping down the the moral hazard implied by deposit insurance are not mutually excluding aims.

The rest of the paper is organized as follows. In Section 2, we review the relevant literature. In Section 3, we present the experimental design. We report our results in Section 4. Section 5 concludes. The instructions for the experiment are relegated to the Appendix.

\section{Related literature}

Our study is rooted in the theoretical literature on bank runs. This literature identifies two polar explanations for the occurrence of bank runs: (i) the worsening of fundamental variables (e.g., macroeconomic shocks) and (ii) coordination failure among depositors (e.g., self-fulfilling prophecy). Empirical evidence suggests that bank runs cannot be explained by changes in the fundamentals alone (Calomiris and Mason, 2003) so coordination problems also play an important role. The idea of sequential decisions is absent in most of the theoretical literature on bank runs, which builds on the seminal paper by Diamond and Dybvig (1983) and considers simultaneous decisions. Gu (2011) incorporates the idea of observability, and focuses on a signal extraction problem in which depositors try to find out whether their bank has fundamental problems or not, so her focus is different from ours.

The paper is mainly related to the empirical literature on deposit insurance and the experimental liter- 
ature on bank runs. The empirical literature on deposit insurance studies issues of the design and implementation, as well as the impact of deposit insurance on bank stability and financial development. This literature identifies partial insurance as an important element of good design (Demirgüc-Kunt et al., 2008), and states that high level of insurance enhances moral hazard that inflicts big damages on financial stability (Demirgüc-Kunt and Detragiache, 2002). The optimal level of deposit insurance, however, is an open theoretical question. There exist many factors that determine the optimal level such as the stage of development of the financial system, the macroeconomic conditions, or the political environment. ${ }^{5}$ In this paper, we leave aside the design of optimal deposit insurance and issues of moral hazard while focusing our attention on studying how different levels of deposit insurance and observability affect the likelihood of a bank run by means of a laboratory experiment.

The experimental literature on bank runs studies factors that favor or prevent bank runs. This literature identifies deposit insurance as an important element that might prevent bank runs. Madies (2006) uses a simultaneous-move, repeated-game framework, and he finds that (i) deposit insurance neither prevents nor stops the propagation of bank runs, as depositors with a $75 \%$ insurance do not behave differently from uninsured depositors, and that (ii) the likelihood of bank runs is higher when the level of deposit insurance is lower, in spite of the ineffectiveness of deposit insurance. ${ }^{6}$ In Schotter and Yorulmazer (2009) depositors observe after each period the number of depositors that have withdrawn and the amount that has been withdrawn, but within any period decisions are simultaneous. In this context, the authors find that deposit insurance guaranteeing $50 \%$ of the initial deposit helps to decrease the occurrence of bank runs, whereas the $20 \%$ insurance level does not affect depositors' behavior compared with the no-insurance case. Our experiment departs from these studies as we are the first to study both simultaneous and sequential setups and different levels of deposit insurance that enables us to investigate the interplay between these variables. Similarly to Madies (2006) we also show that in the simultaneous setup higher level of insurance leads to less bank runs, and we share with Schotter and Yorulmazer (2009) the finding that in a sequential setup partial insurance effectively lowers the the likelihood of bank runs. Moreover, we show that in a sequential setup implementing full insurance does not have an additional decreasing effect.

Another important feature that has been studied in the experimental literature on bank runs are coordination problems. Arifovic et al. (2010) show that when depositors perceive coordination to be difficult, bank runs are more likely to emerge. On the contrary, when coordination is perceived to be easy, depositors'

\footnotetext{
${ }^{5}$ As a result, setting adequate levels of deposit insurance is usually identified as being country-specific. For more detail, see "Deposit Insurance Coverage", a discussion paper by the International Association of Deposit Insurers.

${ }^{6}$ Madies (2006) does not carry out any experimental session with full insurance, because in his view it yields a trivial outcome with no bank run.
} 
behavior is likely to converge to the no-run equilibrium. This result is related to Garratt and Keister (2009), who show that forced withdrawals increase the difficulty of coordination and thus the likelihood of bank runs. ${ }^{7}$ To approach the issue of coordination problems, Kiss, Rodriguez-Lara and Rosa-Garcia (2009) study whether observability may prevent bank runs, whereas Klos and Sträter (2010) test the prediction of the global game of bank runs in a laboratory experiment. None of these studies, however, considers the role of deposit insurance in the emergence of bank runs.

\section{The Setup}

A total of 192 students were recruited from the undergraduate population of the Universidad de Alicante. Students had no (or very little) prior exposure to game theory. The experiment was conducted at the Laboratory of Theoretical and Experimental Economics (LaTEx), using the experimental software z-Tree (Fischbacher, 2007). The laboratory consists of 24 computers in separate cubicles and any form of communication between subjects was strictly forbidden.

We run a total of 8 sessions. In each session, instructions were read aloud with each subject in front of his or her computer. We let subjects ask about any doubts they may have had before starting the experiment. Instructions are in Appendix A. The average length of each session was 45 minutes. Subjects received on average 12 Euros for participating, including the show-up fee.

In each session subjects were divided into two matching groups of 12. Subjects from different matching groups never interacted with each other throughout the session. Subjects within the same matching group were randomly and anonymously matched in pairs at the end of each round, so that we managed efficiently the number of independent observations. Each of these pairs was assigned a third depositor, simulated by the computer so as to create a three-depositor bank in each round. Subjects knew that one of the depositors in the bank was simulated by the computer. We refer to the computer as the impatient depositor whereas the experimental subjects are called patient depositors.

In each session, the three depositors played a coordination problem for 15 rounds. In each round, depositors invested an initial endowment of $e=40$ monetary units in the bank. ${ }^{8}$ Then, they were randomly

\footnotetext{
${ }^{7}$ Forced withdrawals mean that some subjects were not allowed to decide on their own but forced to withdraw. Using forced withdrawals, the authors capture the idea that in crisis times more depositors need to withdraw their funds from the bank, reducing the amount of available liquidity to meet further withdrawals.

${ }^{8}$ We use Spanish pesetas as experimental currency. The reason for this design choice is twofold. First, it mitigates integer problems, compared with other currencies (USD or euros, for example). On the other hand, although Spanish pesetas are no longer in use, Spanish people still use pesetas to express monetary values in their everyday life. In this respect, by using a "real" currency we avoid the problem of framing the incentive structure of the experiment using a scale (e.g., "experimental
} 
assigned a position in the sequence of decision and asked to decide consecutively, as if they were in the line of a bank. Subjects knew their position in the line. It was known that the impatient depositor (i.e., the computer) was programmed to withdraw always, regardless of the position in the sequence. The patient depositors were allowed to decide between waiting or withdrawing in each round. Before making this decision, depositors possibly observed previous decisions (but not types) and they knew whether they would be observed by subsequent depositors. In the experiment, we considered different information structures in each round. ${ }^{9}$

To describe depositors' payoffs, let $y^{i} \in\{0,1\}$ for $i=1,2,3$ denote depositor $i$ 's decision, where 0 denotes keeping the money in the bank, whereas 1 indicates withdrawal. We denote as $c_{1}^{i}$ depositor $i$ 's payoff upon withdrawal and $c_{0}^{i}$ the payoff if she waits for $i=1,2,3$. If a depositor decides to withdraw, she receives her payoff immediately. Payoff upon withdrawal is $c_{1}^{i}=c_{1}=50$ for $i \in\{1,2\}$, and for $i=3$ it is

$$
c_{1}^{3}=\left\{\begin{array}{c}
c_{1}=50 \text { if } \sum_{j \neq 3} y^{j}<2 \\
c_{11}=20 \text { if } \sum_{j \neq 3} y^{j}=2
\end{array}\right. \text {. }
$$

In words, if depositor 1 or 2 withdraws, she receives $c_{1}=50$. This amount corresponds to the depositor's initial endowment $(e=40)$ plus an interest rate of 10 monetary units. If depositor 3 withdraws, she receives $c_{1}^{3}=c_{1}=50$ if she is the first or second withdrawing depositor. If depositor 3 withdraws after two withdrawals, then she gets the remaining funds in the bank $\left(c_{11}=3 e-2 c_{1}=20\right)$ which is less than her initial endowment.

If a depositor chooses to keep the money in the bank, she has to wait until everybody has decided. If both patient depositors wait, then each of them receives 70 monetary units. Deposit insurance becomes effective if there is only one depositor who decides to wait. We study three levels of insurance. In the case of no insurance (NI) the depositor lacks any protection and receives the residual funds the bank has after two withdrawals (20 monetary units). We run two sessions with this treatment. In the case of partial insurance (PI) the only depositor who decides to keep her funds deposited receives a higher payoff (30 monetary units), but this payoff is still smaller than her initial endowment. We run two sessions with this treatment. Full insurance (FI) means that a depositor who chooses to wait cannot lose money, so any depositor who waits receives 40 monetary units. We run four sessions with this treatment. ${ }^{10}$ Payoffs for any patient depositor currency") with no cognitive content.

${ }^{9}$ Subjects faced a different problem in each round. In the experiment we considered all informational setups that may arise with three depositors, so we also had structures with partial information. For instance, depositor 3 may know what depositor 2 has done but she may have no information about depositor 1's decision. Results for the partial environments are similar to those discussed and presented in Appendix B. An interesting question is whether subjects face each round as a "new game" or they learnt how to play. The Chow test reveals that subjects did not behave differently in the second part of the experiment.

${ }^{10}$ In the experiment we did not use the word "deposit insurance". See the Instructions in Appendix A for further details. 
$i \in\{1,2,3\}$ that decides to wait can be summarized as follows:

$$
c_{0}^{i}=\left\{\begin{array}{c}
c_{00}=70 \text { if } \sum_{j \neq i} y^{j}=1 \\
c_{01}^{N I}=20 \text { if } \sum_{j \neq i} y^{j}=2 \\
c_{01}^{P I}=30 \text { if } \sum_{j \neq i} y^{j}=2 \\
c_{01}^{F I}=40 \text { if } \sum_{j \neq i} y^{j}=2
\end{array},\right.
$$

where the first symbol (0) in the subscript shows that depositor $i$ waits, while the second symbol denotes the other patient depositor's decision. Superscripts stand for the treatment.

The payoffs resemble the ex ante optimal contract in Diamond and Dybvig (1983) and allow for coordination problems, satisfying the following relations:

$$
c_{00}>c_{1}>e \geq c_{01}^{S} \geq c_{11}
$$

where $S \in\{N I, P I, F I\}$. A key element of the model is that when depositors decide, they know their position but they may not be sure of the payoff they will receive. For instance, if a patient depositor 2 observes a withdrawal and decides to wait, then her payoff depends on if depositor 1 was the impatient depositor or not. Similarly, if depositor 3 in the simultaneous setup decides to withdraw, she does not know whether she will receive $c_{1}=50$ or $c_{11}=20$.

We define a bank run in the following way.

Definition $1 A$ bank run occurs if at least one patient depositor withdraws.

This is the broadest definition, according to which a withdrawal due to a patient depositor already constitutes a bank run. Hereafter, we study how deposit insurance and observability affect the likelihood of bank runs. We focus on the simultaneous and the sequential setup. In the simultaneous setup, subjects only knew their own position, whereas in the sequential setup they also knew the decisions of predecessor subjects and that their decision would be observed by subsequent subjects.

\section{Experimental Evidence}

In this section we analyze the data gathered during the experimental sessions. The main results and insights are summarized in Table 1. In this table, we report the likelihood of bank runs in each treatment. We present the data for both the simultaneous and the sequential setup separately. The number of observations appears in brackets. 
Table 1. Likelihood of bank runs in each treatment

\begin{tabular}{rccc}
\cline { 2 - 4 } & \multicolumn{3}{c}{ Treatment } \\
\cline { 2 - 4 } & No Insurance (NI) & Partial Insurance (PI) & Full Insurance (FI) \\
\hline \hline Simultaneous & 0.841 & 0.483 & 0.225 \\
& $(120)$ & $(120)$ & $(240)$ \\
\hline Sequential & 0.657 & 0.214 & 0.257 \\
& $(70)$ & $(70)$ & $(140)$ \\
\hline \hline
\end{tabular}

The number of observations appears in brackets. In total, we have 760 observations, each corresponding to a bank with 2 experimental subjects (i.e., observations corr espond to a total of 1520 decisions)

We observe that different levels of deposit insurance affect the likelihood of bank runs in a different way. Table 1 shows that deposit insurance reduces the likelihood of bank runs, as this likelihood is higher when there is no insurance both in the simultaneous and the sequential setup. Other insight is that observability has a crucial effect on the likelihood of bank runs, since they are less likely in the sequential setup except for the case of full insurance. In fact, the third important effect is that observability and deposit insurance do not have an independent effect. Although full and partial insurance affect differently the likelihood of bank runs in the simultaneous setup, it does not seem to be the case in the sequential setup. Moreover, we see that as the level of insurance increases, the likelihood of bank runs in the simultaneous setup decreases. It does not happen in the sequential case, in which increasing the level of insurance from partial to full does not help to reduce the likelihood of bank runs.

In order to clarify the effects of deposit insurance and observability, we estimate a logit model in which the dependent variable is the probability of bank run. ${ }^{11}$ The dummy variables $P I$ and $F I$, take the value 1 when there exists partial and full insurance respectively, being 0 otherwise. We define $S E Q$ as a dummy variable that takes the value 1 if the setup is sequential, and it is 0 if it is simultaneous. We propose the following specification:

$$
\operatorname{Pr}(\text { Bank Run })=F\left(\alpha_{0}+\alpha_{P I} P I+\alpha_{F I} F I+\alpha_{S E Q} S E Q+\alpha_{P I S E Q} P I S E Q+\alpha_{F I S E Q} F I S E Q\right)
$$

where $\digamma(z)=e^{z} /\left(1+e^{z}\right)$ and the variables PISEQ and FISEQ are defined as the product of the two dummy variables PI, FI and SEQ. Thus, PISEQ (FISEQ) allows to determine whether there is some additional effect of having both the sequential setup and the partial (full) deposit insurance, apart from the effect that these features have separately. We run equation (1) over a total of 760 observations, which correspond to 760 banks, each of them with 2 patient depositors and the computer. We report the marginal effects in the column (1) of Table 2. In column (2), the marginal effects of partial and full insurance in the

\footnotetext{
${ }^{11}$ The probit specification yields the same results.
} 
sequential setup are reported.

Table 2. Logit model for the likelihood of bank runs in each setup

\begin{tabular}{|c|c|c|c|c|}
\hline & \multicolumn{4}{|c|}{ Likelihood of Bank Run } \\
\hline & \multicolumn{2}{|c|}{ (1) Simultaneous } & \multicolumn{2}{|c|}{ (2) Sequential } \\
\hline & Marginal Effect & Std. Error & Marginal Effect & Std. Error \\
\hline Partial Insurance (PI) & $-0.355^{* * *}$ & 0.052 & $-0.345^{* * *}$ & 0.053 \\
\hline Full Insurance (FI) & $-0.606^{* * *}$ & 0.046 & $-0.365^{* * *}$ & 0.063 \\
\hline Sequentiality (SEQ) & $-0.234^{* *}$ & 0.077 & . & . \\
\hline PIx SEQ & -0.050 & 0.114 & . & . \\
\hline FI x SEQ & $0.290^{* *}$ & 0.099 & . & . \\
\hline Log-Likelihood & \multicolumn{2}{|c|}{-424.67886} & \multicolumn{2}{|c|}{-161.181} \\
\hline Pseudo R2 & \multicolumn{2}{|c|}{0.1735} & \multicolumn{2}{|c|}{0.1078} \\
\hline Number of Observations & \multicolumn{2}{|c|}{760} & \multicolumn{2}{|c|}{280} \\
\hline
\end{tabular}

We have 760 observations which correspond to 1520 decisions. The second column with 280 observations represents the case when we condition the regression on the sequential setup. The marginal effects reported in Table 2 are significantly different from zero at ${ }^{* * *} 1 \%,{ }^{* *} 5 \%$ or $* 10 \%$ significance level.

The benchmark is the simultaneous setup, when there is neither deposit insurance nor information about other depositors' decisions. In column (1), first we look at the effects that deposit insurance and observability have separately. We observe that when the partial insurance is implemented in the simultaneous setup, the likelihood of bank runs decreases by roughly 35\%; whereas the full deposit insurance reduces this likelihood by approximately $60 \%$. We also see that sequentiality reduces the likelihood of bank runs by roughly $23 \%$. The fact that all these probabilities are significantly different from zero implies that deposit insurance and observability decrease the likelihood of bank runs. If we test the hypothesis that deposit insurance and sequentiality have the same effect on reducing the likelihood of bank runs, we reject that hypothesis at $5 \%$ significance level. (For the null hypothesis $H_{0}: \alpha_{P I}=\alpha_{S E Q}$, we get $\chi_{1}^{2}=5.32$ and $p-$ value $=0.0211$. In the case of the null hypothesis $H_{0}: \alpha_{F I}=\alpha_{S E Q}$, we get $\chi_{1}^{2}=40.80$ and $p-$ value $=0.0000$.) We also reject the null hypothesis that partial insurance and full insurance are equally important so as to reduce the likelihood of bank runs $\left(\chi_{1}^{2}=23.91\right.$ and $p-$ value $\left.=0.0000\right)$. These findings are summarized as follows:

Result 1. Deposit insurance and observability significantly reduce the likelihood of bank runs. We reject the hypothesis that these variables have the same effect. More specifically, we observe that full insurance has the largest effect, followed by partial insurance and observability.

We also want to study the interplay between deposit insurance and observability. In column (1) we see that PISEQ is not significantly different from zero. This indicates that partial insurance and observability do not have any additional joint effect on reducing the likelihood of bank runs apart from the effect that these variables have separately (i.e., the combined effect is the summation of both effects). As a result, we find 
that if there exists partial insurance (observability), introducing observability (partial insurance) significantly decreases the likelihood of bank runs (i.e., we reject both the hypothesis that $H_{0}: \alpha_{S E Q}+\alpha_{P I S E Q}=0$ because $\chi_{1}^{2}=12.85$ and $p-$ value $=0.0003$, and the hypothesis that $H_{0}: \alpha_{P I}+\alpha_{P I S E Q}=0$, because $\chi_{1}^{2}=25.65$ and $p-$ value $\left.=0.0000\right)$. Finally, we also see in column (1) that the marginal effect of FISEQ is positive and significantly different from zero. Therefore, the total effect of having full insurance and a sequential setup is not just the sum of the individual effects. More precisely, full insurance has an additional effect on reducing the likelihood of bank runs once observability is in place (we reject the hypothesis that $H_{0}: \alpha_{F I}+\alpha_{F I S E Q}=0$, given that $\chi_{1}^{2}=29.65$ and $p-$ value $\left.=0.0000\right)$. However, observability does not have any impact on reducing the likelihood of bank runs if full insurance already exists (i.e., we cannot reject the hypothesis that $H_{0}: \alpha_{S E Q}+\alpha_{F I S E Q}=0$ at any common significance level because $\chi_{1}^{2}=0.50$ and $p-$ value $=0.4774)$. We summarize these findings as follows:

Result 2. Once depositors' decisions are observable, both partial and full insurance have a significant additional decreasing effect on the likelihood of bank runs. If we add observability to partial insurance, the likelihood of bank runs significantly decreases. Nevertheless, adding observability to full insurance does not have a significant effect on the likelihood of bank runs.

The fact that observability is still important when depositors are partiallly insured but it ceases to be relevant when they are fully insured suggests a relationship between the optimal level of deposit insurance and observability. In the column (2) of Table 2, we study the impact that both partial and full insurance have on the likelihood of bank runs when depositors decide sequentially. We observe that both levels of deposit insurance decrease this likelihood by roughly 35\%. Statistical test confirms that no significant difference is observed between the impact of partial and full insurance in this setup (i.e., in the regression $\operatorname{Pr}(\operatorname{Bank} \operatorname{Run} \mid \mathrm{SEQ})=F\left(\gamma_{0}+\gamma_{P I}+\gamma_{F I}\right)$, where $\digamma(z)=e^{z} /\left(1+e^{z}\right)$, we fail to reject the null hypothesis $H_{0}: \gamma_{P I}=\gamma_{F I}$, since $\chi_{1}^{2}=0.46$ and $p-$ value $\left.=0.4774\right)$. We summarize this result as follows:

Result 3. If depositors' decisions are not observable, full insurance has a different effect than partial insurance on decreasing the likelihood of bank runs. It is not the case when decisions are observable.

This result is important as it highlights that if financial intermediation is characterized by an information structure that allows observability, then there is no need to provide high level of deposit insurance. The effect of a properly chosen partial insurance cannot be enhanced by full insurance. It has two important consequences. On the one hand, in an environment characterized by plentiful information it may be cheaper to avoid bank runs. On the other hand, these experimental results suggest that the goal of minimizing the 
likelihood of bank runs without increasing unnecessarily the moral hazard can be achieved, at least when agents are able to observe each other.

\section{Conclusion}

We have studied the effects of deposit insurance and observability on the emergence of bank runs by the way of a controlled laboratory experiment. Our empirical results show when depositors' decisions are simultaneous, full and partial insurance significantly decrease the likelihood of bank runs, both level of deposit insurance having a different effect. However, when depositors' decisions are observable, we do not find any significant difference between the effect of full and partial insurance. These results may have important implications for setting the optimal level of deposit insurance, which should depend upon the information that depositors have about other depositors' decisions. Although our paper does not belong to the empirical literature on deposit insurance, we contribute to this literature by suggesting that any optimal deposit insurance scheme should rely upon the information structure. In particular, our data suggest that there is no need to provide full insurance to depositors when the degree of observability is high, so that it seems that in such an environment

preventing bank runs is less costly and minimizing the likelihood of bank runs and keeping down the the moral hazard implied by deposit insurance are not mutually excluding aims.

\section{References}

Andolfatto, D., Nosal, E., Wallace, N., 2007. The role of independence in the Green-Lin DiamondDybvig Model. Journal of Economic Theory 137, 709-715.

Arifovic, J., Jiang, J., and Xu, Y., 2010. Bank Runs as Pure Coordination Failures: Experimental Evidence and Endogenous Evolutionary Learning, mimeo.

Calomiris, C., Mason, J., 2003. Fundamentals, Panics and Bank Distress During the Depression. American Economic Review 93, 1615-47.

Demirgüc-Kunt, A., Detragiache, E., 2002. Does deposit insurance increase banking system stability? An empirical investigation. Journal of Monetary Economics 49, 1373-1406

Demirgüc-Kunt, A., Kane, E. J., Laeven, L., 2008. Deposit Insurance around the World: Issues of Design and Implementation. Cambridge, MA:The MIT Press 
Deposit Insurance Coverage, Discussion Paper, Prepared by the Research and Guidance Committee International Association of Deposit Insurers, retrieved from http://www.iadi.org ${ }^{12}$

Ennis, H. M., Keister, T., 2009. Run equilibria in the Green-Lin model of financial intermediation. Journal of Economic Theory 144, 1996-2020.

Garratt, R., Keister, T., 2009. Bank runs as coordination failures: An experimental study. Journal of Economic Behavior and Organization 71, 300-317.

Green, E.J., Lin, P., 2000. Diamond and Dybvig's classic theory of financial intermediation: What's missing?. Federal Reserve Bank of Minneapolis Quarterly Review 24, 3-13.

Gu, C., 2011. Herding and Bank Runs, Journal of Economic Theory 146, 163-188.

Iyer, R., Puri, M., 2008. Understanding Bank Runs: The Importance of Depositor-Bank Relationships and Networks. NBER Working Paper No. 14280.

Kelly, M., O Grada, C., 2000. Market Contagion: Evidence from the Panics of 1854 and 1857. American Economic Review 90, 1110-1124

Kiss, H.J., Rodriguez-Lara, I., Rosa-García, A., 2009. Do Social Networks Prevent Bank Runs? IVIE Working Papers, Serie AD 2009-25

Klos, A., Sträter, N., 2010. Level-1 Thinking in an Experimental Bank Run Gam, mimeo.

Madies, P., 2006. An Experimental Exploration of Self-Fulfilling Banking Panics: Their Occurrence, Persistence, and Prevention. Journal of Business 79, 1831-1866.

Schotter, A., Yorulmazer, T., 2009. On the dynamics and severity of bank runs: An experimental study. Journal of Financial Intermediation 18, 217-241.

Sprague, O.M.W., 1910. History Of Crises Under The National Banking System. Washington, DC: U.S. Government Printing Office.

Starr, M.A., Yilmaz, R., 2007. Bank Runs in Emerging-Market Economies: Evidence from Turkey's Special Finance Houses. Southern Economic Journal 73, 1112-1132.

Wicker, E., 2001. The Banking Panics of the Great Depression. Cambridge: Cambridge University Press.

\footnotetext{
${ }^{12}$ Full url:

http://www.iadi.org/docs/IAD_Coverage_Limit_Guidance_Paper_August_10_2009-For_website_public_consultation.pdf Visited on June 30th 2010
} 


\section{Appendix A: Instructions}

\section{Welcome to the experiment! ${ }^{13}$}

This is an experiment to study decision making, so we are not interested in your particular choices but in individuals' average behavior. Therefore, during the experiment you'll be treated anonymously. Neither the experimenters nor the people in this room will ever know your particular choices.

Next, you will find the instructions on the computer screen explaining how the experiment unfolds. The instructions are the same for all subjects in the laboratory and will be read aloud by the experimenters. It is important for you to understand the experiment before starting, as the money that you will earn will depend on your choices. You also have a copy of the instructions on your table.

\section{Number of rounds}

This experiment has 18 rounds in total. The first 3 rounds are for you to become familiar with the software. The remaining 15 rounds will be used to determine your final payoff, so please be sure that you understand the experiment before starting the 4 th round. This will help you to earn more money.

\section{What is this experiment about?}

At the beginning of each round, you will be provided a certain amount of money ( 40 pesetas) to be deposited in a bank. The same will be done with two other depositors. The bank in which you will invest your money will be formed by 3 depositors: one of them is you, the other one is someone else in this room and the third depositor is simulated by the computer. Therefore, the bank in which you deposit your money will have 120 pesetas per round in total.

\section{Choice and earnings}

In principle, your decision is to choose whether to withdraw your money from the common bank in the first period or to wait until the second period, taking into account that your earnings will depend not only on your choice but also on other depositors' choices. Indeed, it is important to know that the computer will always withdraw her money and, thus that your earnings in each round will only depend on your choice and the choice of the other depositor in this room.

Specifically, if you both wait until the second period to withdraw your money, you will get 70 pesetas, corresponding to your initial investment plus interests generated during the first period of time (in which

\footnotetext{
${ }^{13}$ Instructions are originally in Spanish.
} 
you have decided to wait).

If only one of you withdraws the money, then the one who withdraws takes 50 pesetas (exactly the same amount that the computer will take in this case).

[Treatment NI] The depositor who waits will receive the remaining 20 pesetas. You can think that the bank needs that you both wait to carry out a project, so if one of you withdraws, then the bank cannot invest in the project and pays 20 pesetas to the depositor that has waited.

[Treatment PI] The depositor who waits will receive 30 pesetas. In this case, this depositor receives the amount that remains in the bank after the first period -20 pesetas- plus an additional quantity of interest (10 pesetas).

[Treatment FI] The depositor who waits will receive 40 pesetas. In this case, this depositor receives the amount that remains in the bank after the first period -20 pesetas- plus an additional quantity of interest (20 pesetas).

Finally, it might be the case that you both withdraw your money in the first period. As a result, your earnings will depend on the available amount in the bank and your position in the line. Therefore, if you are at Position 1 or Position 2 in the line and decide to withdraw, you will take 50 pesetas, but if you are the last one in the line (Position 3), only 20 pesetas will remain in the bank and this is exactly the amount of money that you will receive.

Therefore, your payoffs can be summarized in the following table:

[Notice that the value of $c_{01}^{S}$ depends on the treatment, so we presented a different table in each treatment, where $c_{01}^{N I}=20, c_{01}^{P I}=30$ and $\left.c_{01}^{F I}=40\right]$

\begin{tabular}{|c|c|c|c|}
\cline { 3 - 4 } \multicolumn{2}{c|}{} & \multicolumn{2}{c|}{ If you wait then... } \\
\hline $\begin{array}{c}\text { Number of previous } \\
\text { withdrawals }\end{array}$ & If you withdraw & $\begin{array}{c}\text { If the other depositor in the room waits } \\
\text { and only the computer withdraws }\end{array}$ & $\begin{array}{c}\text { If the other depositor in the room } \\
\text { and the computer withdraw }\end{array}$ \\
\hline 0 & 50 & 70 & $c_{01}^{S}$ \\
\hline 1 & 50 & 70 & $c_{01}^{S}$ \\
\hline 2 & 20 & Not applicable & $c_{01}^{S}$ \\
\hline
\end{tabular}

Please remember that the depositor simulated by the computer will always withdraw the money in the first period.

Before starting, it may be important for you to consider that:

1. The person with whom you are linked will change every round. As a result, do not think that you are going to play with the same person. 
2. You will always know your position in the line, but this position might change in each round. In particular, you may be located at Position 1, Position 2 or Position 3 with the same probability. The same is true for the computer.

3. In each round, you will have different information about what other depositors at your bank have done. Therefore, in some cases, you will know what has happened before you arrived at the bank (number of waitings and withdrawals) and in some other cases, you will not. At the time of making your choice, you will also know whether someone else will observe your decision. It may be of your interest to consider this information when making your decision. The information will appear at the left-hand side of the computer screen:

E.g., You are at Position 1. Depositors at Position 2 and Position 3 will observe your choice.

E.g., You are at Position 2. Depositor at Position 1 has waited. Depositor at Position 3 will not observe your choices

We are now going to start with the first three rounds. At the end of the three rounds, you can ask any questions to make sure that you have understood the procedure. If you have any doubt afterwards, please raise your hand and remain silent. You will be attended by the experimenters as soon as possible. Talking is forbidden during this experiment.

\section{Appendix B}

Here we report the effect of partial information on the likelihood of bank runs. Recall that we have three depositors in the line of a common bank so that there are 8 possible information structures depending on who observes whom. To model these structures we use networks.

A network $(\Gamma)$ is the set of existing links among the depositors. Two depositors are neighbors if a link connects them. A link is represented by a pair of numbers $i j$ for $i, j \in\{1,2,3\}, i<j$. For instance, 12 denotes that depositor 1 and depositor 2 are linked, therefore depositor 1 knows that depositor 2 will observe her decision, and depositor 2 chooses after observing depositor 1's decision. As detailed in the text, when depositor $i$ has to decide she knows: (a) the decisions of neighbors who acted earlier, and (b) whether her decision would be observed by neighbors deciding later. Depositor $i$ also knows her position in the line but the network structure is not commonly known (i.e., information is local, therefore no depositor knows if the other two depositors are connected or not).

In our experiment, links were independent of types, so depositors of the same type were not more likely to be linked nor was there any relationship between types and the number of links. Subjects were aware of 
these features and knew that the information structure was exogenously given (i.e., it was not the depositor's choice to decide her position in the line or the number of links). Finally, it was commonly known that position in the line, network structure, or both changed at each round.

We considered all the possible networks: $(12,23,13),(12,23),(12,13),(13,23),(12),(13),(23),(\emptyset)$, where $(\emptyset)$ stands for the empty network which has no links at all while the structure $(12,23,13)$ contains all the possible links and is called the complete network. The empty network can be interpreted as a simultaneousmove game where depositors have no information about other depositors' decisions as in Diamond and Dybvig (1983). On the other extreme, the complete network represents a sequential setup, meaning that depositors observe predecessors' decisions. In Section 4, we compared these information setups. Now, we extend our analysis for the case of partial information.

In order to study how links affect the likelihood of bank runs, we define Lij as a dummy variable that takes the value 1 if the link $i j$ is present, being 0 otherwise. Using the notation in Section 4 , we define $P I$ and FI as two dummy variables that take the value 1 in the case of partial and full insurance respectively, being 0 otherwise. In addition, we define $S E Q$ as a dummy variable that takes the value 1 when the setup is sequential, being zero otherwise (i.e., $S E Q \equiv L 12 L 13 L 23) .{ }^{14}$ We then propose the following specification:

$$
\begin{aligned}
\operatorname{Pr}(\text { Bank Run })= & F\left(\alpha_{0}+\alpha_{L 12} L 12+\ldots+\alpha_{L 12 L 23} L 12 L 23+\alpha_{S E Q} S E Q+\right. \\
& +\alpha_{P I} P I+\alpha_{P I L 12} P I L 12+\ldots . \alpha_{P I L 12 L 23} P I L 12 L 23+\alpha_{P I S E Q} P I S E Q+ \\
& \left.+\alpha_{F I} F I+\alpha_{F I L 12} F I L 12+\ldots . \alpha_{F I L 12 L 23} F I L 12 L 23+\alpha_{F I S E Q} F I S E Q\right)
\end{aligned}
$$

where $\digamma(z)=e^{z} /\left(1+e^{z}\right)$ and the composite dummy variables (e.g., L12L23, PIL12,...) are defined as the product of other dummies to introduce flexibility in the model. In the following table, we report the

\footnotetext{
${ }^{14}$ Again, $S E Q$ is used to denote the sequential setup. However, the variable is not defined as in Section 4 . In Section $4, S E Q$ took the value $1(0)$ in the sequential (simultaneous) setup. Now, $S E Q$ is 0 when there is partial information or no information at all.
} 
marginal effects and the standard errors. Then, we present our main findings.

Table 3. Logit model for the likelihood of bank runs in the case of partial information

\begin{tabular}{|c|c|c|c|c|c|}
\hline & \multicolumn{5}{|c|}{ Likelihood of bank run } \\
\hline & Marginal Effect & Std. Error & & Marginal Effect & Std. Error \\
\hline L12 & -0.015 & 0.125 & PIL13L23 & $-0.314^{* *}$ & 0.139 \\
\hline L13 & 0.029 & 0.133 & PIL12L23 & $-0.282^{* *}$ & 0.146 \\
\hline L23 & -0.119 & 0.113 & PISEQ & $0.427 * *$ & 0.217 \\
\hline L12L13 & -0.172 & 0.175 & FI & $-0.612^{* * *}$ & 0.045 \\
\hline L13L23 & 0.274 & 0.210 & FIL12 & 0.084 & 0.147 \\
\hline L12L23 & 0.083 & 0.192 & FIL13 & 0.066 & 0.154 \\
\hline SEQ & -0.282 & 0.207 & FIL23 & 0.088 & 0.144 \\
\hline PI & $-0.365^{* * *}$ & 0.052 & FIL12L13 & -0.016 & 0.227 \\
\hline PIL12 & -0.077 & 0.148 & FIL13L23 & -0.218 & 0.197 \\
\hline PIL13 & -0.027 & 0.160 & FIL12L23 & -0.011 & 0.224 \\
\hline PIL23 & 0.181 & 0.148 & FISEQ & 0.316 & 0.287 \\
\hline PIL12L13 & 0.140 & 0.249 & & & \\
\hline Log-Likelihood & & & -911.88934 & & \\
\hline Pseudo R2 & & & 0.1760 & & \\
\hline
\end{tabular}

The number of banks that were observed was 1440 that corresponds to 2880 individual decisions (In each session, 12 banks with two subjects playing 15 rounds. For the full-insurance treatment we had 4 sessions, whereas we run 2 sessions for each of the other treatments.) The marginal effects are significantly different from zero at ${ }^{* * *} 1 \%,{ }^{* *} 5 \%$ or $* 10 \%$ significance level.

Again, the benchmark is the simultaneous setup in which there is neither deposit insurance nor information about other depositors' decisions. As dicussed in Section 4, we see that (i) both partial and full insurance significantly reduce the likelihood of bank run (by $37 \%$ and $61 \%$ respectively), and that (ii) full insurance has more effect than partial insurance (i.e., we reject the hypothesis that $H_{0}: \alpha_{P I}=\alpha_{F I}$ because $\chi_{1}^{2}=23.91$ and $p-$ value $\left.=0.0000\right)$.

To see whether a given network is able to reduce the likelihood of bank runs, we have to consider the sum of the coefficients of the links in the network and to test if it is significant. From the regression presented in Table 3 follows that none but the complete network decreases the likelihood of bank runs. $\left(H_{0}: \alpha_{L 12}+\alpha_{L 13}+\alpha_{L 23}+\alpha_{L 12 L 13}+\alpha_{L 12 L 23}+\alpha_{L 13 L 23}+\alpha_{S E Q}=0\right.$ is rejected because $\chi_{1}^{2}=8.26$ and $p-$ value $=0.004$, while there is no other network where such hypothesis is rejected.)

We reject the hypothesis that observability (i.e., the complete network) does not have a significant effect on reducing the likelihood of bank runs under partial insurance $\left(H_{0}: \alpha_{P I L 12}+\alpha_{P I L 13}+\alpha_{P I L 23}+\alpha_{P I L 12 L 13}+\right.$ $\alpha_{P I L 12 L 23}+\alpha_{P I L 13 L 23}+\alpha_{P I S E Q}=0 ; \chi_{1}^{2}=0.18$ and $p-$ value $\left.=0.667\right)$. However, we do not reject the hypothesis under full insurance $\left(H_{0}: \alpha_{F I L 12}+\alpha_{F I L 13}+\alpha_{F I L 23}+\alpha_{F I L 12 L 13}+\alpha_{F I L 12 L 23}+\alpha_{F I L 13 L 23}+\right.$ $\alpha_{F I S E Q}=0 ; \chi_{1}^{2}=7.64$ and $p-$ value $\left.=0.006\right)$.

We define $\beta_{P I, S E Q}=\alpha_{P I}+\alpha_{P I L 12}+\alpha_{P I L 13}+\alpha_{P I L 23}+\alpha_{P I L 12 L 13}+\alpha_{P I L 12 L 23}+\alpha_{P I L 13 L 23}+\alpha_{P I S E Q}$ 
and $\beta_{F I, S E Q}=\alpha_{F I}+\alpha_{F I L 12}+\alpha_{F I L 13}+\alpha_{F I L 23}+\alpha_{F I L 12 L 13}+\alpha_{F I L 12 L 23}+\alpha_{F I L 13 L 23}+\alpha_{F I S E Q}$. The former (latter) considers the marginal effect that the complete network and partial (full) insurance have with respect to the benchmark case. We cannot reject the hypothesis that $H_{0}: \beta_{P I, S E Q}=\beta_{F I, S E Q}$ because $\chi_{1}^{2}=0.46$ and $p-$ value $=0.495$. Thus, full and partial insurance have a similar effect under the complete network.

If we study the difference between partial and full insurance in any given network, we find no differences at the $5 \%$ significance level, except in the case of the empty network (the simultaneous case) and the network that contains only the link $\{L 23\} .{ }^{15}$ This result shows that a higher level of deposit insurance is more effective when depositors do not have information about their predecessors, specifically when the first depositor's decision is not observed.

\footnotetext{
${ }^{15}$ In order to test if partial and full insurance have a similar effect in a given network, we have to test if the marginal effect they add is similar. For instance, to test if both are similar in the network $\{12,23\}$ we have to test $H_{0}: \alpha_{P I}+\alpha_{P I L 12}+$ $\alpha_{P I L 23}+\alpha_{P I L 12 L 23}=\alpha_{F I}+\alpha_{F I L 12}+\alpha_{F I L 23}+\alpha_{F I L 12 L 23}$. In this case, the hypothesis is not rejected, with $\chi_{1}^{2}=1.09$ and $p-$ value $=0.298$. For the network $\{23\}$ the hypothesis $H_{0}: \alpha_{P I}+\alpha_{P I L 23}=\alpha_{F I}+\alpha_{F I L 23}$ is rejected with $\chi_{1}^{2}=11.59$ and $p-$ value $=0.000$. Tests for the rest of networks are available upon request.
} 